\title{
Knowledge and Awareness of End-of-life Care among Doctors Working in Intensive Care Units at a Tertiary Care Center: A Questionnaire-based Study
}

\author{
Kritika Agrawal $^{1}$, Rakesh Garg ${ }^{2}$, Sushma Bhatnagar ${ }^{3}$
}

\begin{abstract}
Introduction: End-of-life care (EOLC) is an increasingly important concern in the management of terminally ill patients. Effective EOLC depends significantly on the physicians working in the critical care units. Thus, adequate knowledge of critical care professionals regarding EOLC is important. We conducted this study to evaluate the awareness and knowledge of doctors working in critical care units toward EOLC.

Materials and methods: Doctors working in critical care units were invited to fill paper-based questionnaire. The validated questionnaire was constructed based on the existing literature on EOLC and expert opinion. The questionnaire comprised four sections: demographic details, experience with EOLC situations, general awareness of EOLC, and specific awareness of EOLC in clinical practice. The collected data were analyzed by descriptive analysis.

Results: Most respondents had not counseled more than five families regarding EOLC over 1 month. Majority of the respondents (81.7\%) had heard of EOLC; the major source of information being their work in the concerned specialty. Only $29.2 \%$ of the respondents applied EOLC principles in their clinical practice. Main barriers were lack of information and training. Only $20.3 \%$ of the respondents were aware of Indian guidelines about EOLC. Majority of the respondents disagree regarding the usage of critical care units and resuscitation of terminally ill patients and were in favor of home care. One-third respondents felt uncomfortable in discussing EOLC issues with the families. Half of the respondents felt that they were only somewhat competent in managing EOLC issues. Most respondents opined that training and education in medical curriculum for terminally ill patients are lacking and were in strong favor of inclusion of specific training for the same.

Conclusion: The EOLC needs to be an integral part of critical care management and teaching curriculum. An integral referral system may also be an option for various advance disease patients getting treatment from critical care specialists for EOLC decision.

Keywords: Awareness, Critical care unit, Doctors, End-of-life care, Intensivist, Knowledge, Palliative care.

Indian Journal of Critical Care Medicine (2019): 10.5005/jp-journals-10071-23293
\end{abstract}

\section{INTRODUCTION}

The rapidly advancing medical science and technology discovered cures for many of the previously incurable diseases, thus, leading to a longer life expectancy. However, this prolonged life span is not without its fallacies. The end stage of life is becoming more and more fraught with incapacities and suffering; thus, sparking a rise in interest in end-of-life care (EOLC). The principal aim for provision of EOLC to critically ill patients is providing a milieu for "good death" in the terminal stage of life. ${ }^{1}$

Management of critically ill patient involves not only symptomatic management but also discussion and communication regarding their prognosis and the pertinent end-of-life care (EOLC) decisions. ${ }^{2}$ The physicians should, therefore, be adept in communication and should be well versed with the various end-of-life issues and their implications. ${ }^{3}$ Clinicians worldwide are realizing the futility of unnecessary prolongation of the dying process and are adopting a more humane approach toward these patients. ${ }^{2,4-7}$ However, the awareness and acceptability for EOLC among critical care specialists appear to be unsatisfactory. Though the efforts made by critical care and palliative care societies have helped in making significant headway, the scenario of EOLC is still in an evolving stage in India. In India, various barriers act as hindrances to effective EOLC. Prolongation of the terminal stage of life not only heightens the suffering of the patients and their families but also imposes a considerable economic burden on the country. ${ }^{1,8,9}$ The critical care unit receives many critically
${ }^{1-3}$ Department of Onco-anesthesia and Palliative Medicine, Dr BRA Institute-Rotary Cancer Hospital, All India Institute of Medical Sciences, New Delhi, India

Corresponding Author: Rakesh Garg, Department of Onco-anesthesia and Palliative Medicine, Dr BRA Institute-Rotary Cancer Hospital, All India Institute of Medical Sciences, New Delhi, India, Phone: +91 9810394950, e-mail: drrgarg@hotmail.com

How to cite this article: Agrawal K, Garg R, Bhatnagar S. Knowledge and Awareness of End-of-life Care among Doctors Working in Intensive Care Units at a Tertiary Care Center: A Questionnaire-based Study. Indian J Crit Care Med 2019;23(12):568-573.

Source of support: Nil

Conflict of interest: None

ill patients with terminal illness, so imparting EOLC is primarily based on doctors working in these critical care units. It is thus of paramount importance that these health professionals have adequate knowledge and information related to EOLC, concerns, decisions, and management.

Though there is emerging literature regarding EOLC in India as well, extensive search of literature did not reveal any reported study to assess the knowledge and awareness of critical care professionals for EOLC. 1,8,10,11 The primary aim of this study was to assess the awareness and knowledge of doctors who have worked in critical care units toward EOLC in critically ill patients. 


\section{Materials and Methods}

This cross-sectional volunteer-based study was performed in doctors working in critical care units of a tertiary care center after receiving the approval from the Institutional Ethics Committee. The inclusion criteria included doctors working in intensive care units (ICU), of any specialty, of either gender, having at least 3 months of completely dedicated adult ICU postings in the past 3 years, and willingness to participate in the study. Those consenting to participate were informed about the nature of the survey.

A paper-based standardized questionnaire was distributed to the participants and their responses were collected anonymously. During the questionnaire filling, the respondents were not allowed to refer to any literature from any source or discuss the questions with their colleagues. The filled questionnaire was checked for its completeness and if any part was left unanswered the respondent was requested to answer it as well.

\section{Development of Study Tool}

There is no validated tool for assessment of knowledge and awareness related to EOLC among doctors working in critical care setup. After a thorough review of the published literature using various search engines including PubMed, Medline, Scopus, Cochrane, Google Scholar, we collected relevant questions that would assess the status of awareness and knowledge related to EOLC among the doctors working in critical care setup.

The study tool was designed via a three-step process of tool development. The process includes content domain, sampling from content (item generation), and instrument construction. The content of questionnaire was collected based on literature review with regard to various parameters for assessment of awareness and knowledge related to end-of-life issues. Also, opinion was obtained from subject experts regarding the potential contents to be assessed for the purpose of assessing awareness of end-oflife issues in caregivers. Based on these sources, a set of questions were generated. The questionnaire so generated was provided to palliative care professionals having sufficient knowledge and experience ( $>3$ years) of EOLC (five subject experts) to assess for any ambiguity, missing contents, relevancy or representativeness, clarity, and comprehensiveness of the various items included in the questionnaire. They evaluated the questionnaire for face and content validation. The feedback was analyzed and revision was made in the questionnaire. The final questionnaire was developed through a consensus method after taking inputs from the experts. This questionnaire was provided to 10 doctors ( 5 doctors working in palliative care or critical care and 5 doctors not working in palliative care or critical care) to comment on the understanding of the different items of the questionnaire. Their feedbacks were analyzed and the questionnaire was modified accordingly. Finally, operational instrument was constructed after the final generated items were refined and organized in the proper format and sequence.

\section{Research Tool}

The questionnaire comprised various sections:

Part I comprised about the demographic details of the doctor working in the ICU: the first part of the questionnaire comprised the demographic details of the doctor, i.e., age, gender, designation, specialty, and ICU experience.

Part II contained the statements related to experience with EOLC situations: the second part assessed the respondents' experience with respect to EOLC situations such as dealing with terminally ill patients, counseling of these patients and their families regarding the prognosis and the possibility of organ donation, etc.

Part III contained the statements related to general awareness of EOLC: the third part of the research tool enquired about the general awareness of the respondents toward EOLC. They were asked about their source of knowledge, their self-assessment of their knowledge, any formal training, etc. Their application of EOLC practices in clinical practice was also assessed and efforts were made to elucidate the hindrances for the same.

Part IV contained the statements related to specific awareness of EOLC: in this section, detailed questions were asked to evaluate the specific knowledge and awareness of various aspects of EOLC such as withholding of life support, home care/hospice care of terminally ill patients, management of pain, sedation, nutrition, etc. The respondents' comfort level in dealing with such patients, explaining the prognosis, and discussing EOL issues with the patients/families was also assessed.

In the questionnaire, the residents who were still doing their postgraduate course were termed "postgraduates" (PGs), while those had completed the 3 years of postgraduation in their respective specialty were termed "senior residents" (SRs).

\section{Statistical Analysis}

To the best of our knowledge, there is no validated questionnaire for evaluating the knowledge and attitude of doctors regarding EOLC in current literature. Thus, a formal sample size calculation was not feasible. So we included around 200 doctors for the study. This number was considered sufficient to comment on various domains of EOLC among doctors in critical care setup. The collected data have been depicted as frequency (percentage) or mean \pm standard deviation (SD) as appropriate. The data were analyzed by descriptive analysis to assess the status of awareness and knowledge related to EOLC. The correlation of the demographic profile of the respondents with various components of knowledge and awareness of EOLC was evaluated using Chi-square test, one-way analysis of variance (ANOVA), Kruskal-Wallis, and Dunn's test.

\section{Results}

A paper-based standardized questionnaire was distributed to the participants and their responses were collected anonymously over a period of 7 months (January-July 2018). We approached a total of 255 participants; of which 39 did not give consent (response rate $84.7 \%$ ) and 14 submitted incompletely filled forms, thereby resulting in an analytic sample of 202 (79.2\%) participants. The demographic characteristics of the respondents are shown in Table 1.

\section{Experience with EOLC Situations}

The experiences of respondents with EOLC situations varied widely. Majority of the respondents had attended to and counseled three to five terminally ill patients and their families over the preceding 1 month. However, almost $80 \%$ of the respondents did not have any experience of counseling any family regarding organ donation (Fig. 1).

\section{General Awareness and Knowledge of EOLC}

Majority of the respondents (81.7\%) had heard of EOLC; the foremost source of information being via their work in their concerned specialty (Fig. 2). Most of the critical care specialists were lacking knowledge of EOLC (Table 2). 
Only $11.4 \%$ of the respondents had taken any training related to EOLC. Though $45.1 \%$ of them had studied literature associated with EOLC, only $20.3 \%$ were aware about the existence of any Indian guidelines pertaining to EOLC. Only about one third (29.2\%) of the respondents applied EOLC principles in their clinical practice. The major causes of this were lack of adequate information and training about EOLC. Personal ethical/moral concerns or social/ cultural taboos were perceived to be barriers by less than $10 \%$ of the participants. More than half (53.5\%) of the respondents were aware of the concept of "good death" and 61.9\% respondents felt that they could identify a terminally ill patient with reasonable certainty.

Of the total respondents, nearly half of them tended to disagree regarding the necessity of resuscitation and ICU care in all terminally ill patients and felt that home care should be encouraged for such patients (Table 3). Majority (61.9\%) were of the opinion that critically ill patients/their families should have the right to choose to

Table 1: Demographic data for respondents $(n=202)$

\begin{tabular}{ll}
\hline Variable & Frequency; $n$ (\%) \\
\hline Gender & $114(56.4)$ \\
Male & $88(43.6)$ \\
Female & \\
Designation & $43(21.4)$ \\
PG & $157(78.1)$ \\
SR & $1(0.5)$ \\
Fellow & \\
Specialty & $135(66.8)$ \\
Anesthesiology & $36(17.8)$ \\
Critical care & $5(2.5)$ \\
Internal medicine & $3(1.5)$ \\
Neurology & $10(4.9)$ \\
Neurosurgery & $8(4.0)$ \\
Pulmonary medicine & $5(2.5)$ \\
Infectious diseases & $30.3 \pm 2.5$ \\
Age (years); mean \pm SD & $48.0 \pm 18.1$ \\
Experience in concerned specialty (months); & \\
mean \pm SD & $13.2 \pm 11.2$ \\
Total ICU experience (months); mean \pm SD & \\
\hline PG, postgraduate; SR, senior resident; SD, standard deviation; ICU, intensive \\
care unit
\end{tabular}

discontinue life support interventions. However, 37.1\% respondents agreed and $33.2 \%$ disagreed that explaining a terminal prognosis imparts a sense of hopelessness in the family members. Almost half of them also felt that providing EOLC required a certain amount of emotional detachment.

Only $37.6 \%$ of the respondents were "aware" and $38.1 \%$ were "somewhat aware" of hospice as a type of care for the terminally ill (Table 4). Though majority of the respondents felt comfortable or somewhat comfortable in discussing EOLC issues with the families of terminally ill patients but that comfort did not extend to discussion of organ donation in more than half of the participants. Most of the respondents opined that the adequacy of training and education in the medical curriculum for dealing with terminally ill patients and their EOLC issues was "somewhat" (39.1\%) or "not at all" (48.5\%). More than $90 \%$ agreed or strongly agreed that specific training about EOLC should be included in the medical curriculum.

When questioned about their comfort in discussing specific EOLC issues with the families; most of the participants were either somewhat comfortable or somewhat uncomfortable in the discussion (Table 5).

Nearly $50 \%$ of the respondents opined that they were competent to handle patient/family interactions regarding EOLC issues with minimal supervision, whereas approximately $25 \%$ felt that they needed close supervision or coaching (Table 6).

More than half of the respondents perceived themselves to be only somewhat competent in managing EOLC issues, e.g., pain, delirium, dyspnea, etc., (Table 7).

\section{Association of Demographic Profile with Various Components of Knowledge and Awareness of EOLC in Doctors Working in Critical Care Units}

In stepwise multivariate regression analysis, various studied parameters were assessed for independent association with the improved clinical applicability of EOLC. On analysis, study of EOLC literature [adjusted odds ratio $(O R)=7.09,95 \%$ confidence interval (CI) 3.15-15.98], understanding of EOLC (adjusted OR $=7.46,95 \%$ $\mathrm{Cl}$ 1.62-34.29), and awareness of good death (adjusted $\mathrm{OR}=1.5$, $95 \% \mathrm{Cl} 0.95,2.37)$ were independently associated with an improved clinical applicability of EOLC.

The individual parameters were also analyzed for its correlation to particular relevant outcome parameters. No statistically significant correlation was observed between the gender of the doctors

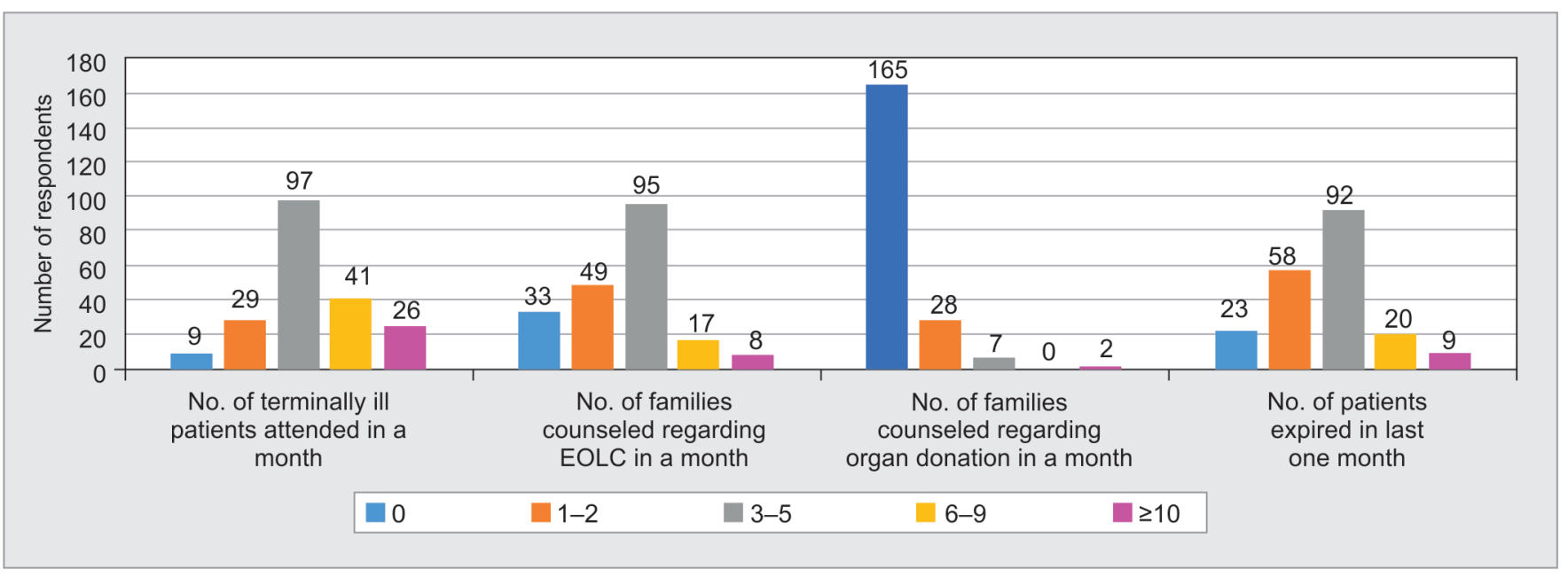

Fig. 1: End-of-life care experience of respondents 
and their awareness of EOLC ( $p=0.437)$. Although a statistically significant relation was observed with respect to age, the difference in age was not practically relevant $(p=0.002)$. Senior residents $(p=0.002)$ and those with more experience (median experience of 48 months vs 36 months) in their concerned specialty ( $p=0.002)$ were more aware of EOLC. However, the months of ICU experience did not affect the awareness of EOLC $(p=0.169)$. Awareness was more in doctors specializing in the field of anesthesia, critical care, infectious diseases, and pulmonary medicine as compared to internal medicine, neurology, and neurosurgery. The awareness of

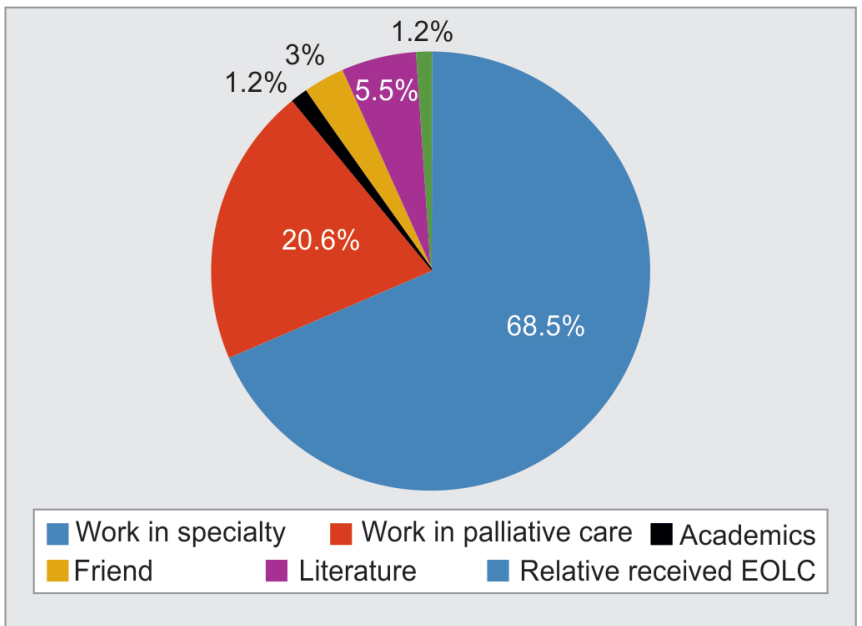

Fig. 2: Source of information on end-of-life care

Table 2: Knowledge of EOLC among critical care specialists $(n=202)$

\begin{tabular}{lc}
\hline $\begin{array}{l}\text { Self-assessment of knowledge } \\
\text { of EOLC }\end{array}$ & Frequency; $n$ (\%) \\
\hline Very knowledgeable & $4(2.0)$ \\
Quite a bit of knowledge & $38(18.8)$ \\
Some knowledge & $116(57.4)$ \\
No knowledge & $25(12.4)$ \\
Do not know & $19(9.4)$ \\
\hline
\end{tabular}

EOLC, end-of-life-care good death also paralleled the awareness of EOLC, with designation, specialty, and overall experience having significant relation with it ( $p=0.003,0.001$, and 0.0001 , respectively).

We did not find any statistically significant relation between gender, designation, specialty, experience in concerned specialty, and total ICU experience with the possibility of having taken training related to EOLC ( $p=0.264,0.094,0.107,0.2024$, and 0.2985 , respectively). Although a statistically significant relation was observed with respect to age, the difference in age was not practically relevant $(p=0.0423)$.

Application of EOLC principles in clinical practice did not vary with gender, specialty, or total ICU experience $(p=0.486,0.085$, and 0.0642 , respectively). Clinical application improved in SRs and in those with longer experience in their specialty $(p=0.003$ and 0.0257 , respectively). Although a statistically significant relation was noted with respect to age, the difference in age was not practically relevant ( $p=0.0262)$.

The doctors' ability to identify a terminally ill patient with reasonable certainty did not show any significant relation with their age, gender, designation, specialty, or experience $(p=0.2758$, $0.539,0.575,0.619$, and 0.2899 , respectively).

The level of doctors' comfort in discussing EOLC issues with families of critically ill patients did not show significant variation with gender, designation, or specialty $(p=0.198,0.056$, and 0.091 , respectively). Although a statistically significant relation was observed with respect to age, the difference in age was not practically relevant $(p=0.0000)$. Residents with more experience in their specialty (median experience of 48 months vs 43 months) or in ICU (median experience of 12 months vs 8 months) depicted significantly more comfort in such discussions ( $p=0.0493$ and 0.0312 , respectively).

\section{Discussion}

We observed from our study that majority of the respondents were aware of the concept of EOLC and good death but most had only "some knowledge" about EOLC. The awareness, however, translated to clinical application in only around one third of the respondents. Lack of adequate training and information were reported to be the most frequent hindrances. It was therefore not surprising that

Table 3: Knowledge of EOLC principles $(n=202)$

\begin{tabular}{|c|c|c|c|c|c|}
\hline & Strongly agree & Agree & $\begin{array}{l}\text { Neither agree nor } \\
\text { disagree }\end{array}$ & Disagree & Strongly disagree \\
\hline $\begin{array}{l}\text { Do you think resuscitation should always be done in a } \\
\text { terminally ill patient? }\end{array}$ & $5(2.5)$ & $34(16.8)$ & $32(15.8)$ & $96(47.5)^{*}$ & $35(17.3)$ \\
\hline $\begin{array}{l}\text { Do you think ICU care should always be done in a } \\
\text { terminally ill patient? }\end{array}$ & $3(1.5)$ & $31(15.3)$ & $35(17.3)$ & $96(47.5)^{*}$ & $37(18.3)$ \\
\hline $\begin{array}{l}\text { Do you think home care should be advocated for a } \\
\text { terminally ill patient? }\end{array}$ & $38(18.8)$ & $89(44.1)^{*}$ & $44(21.8)$ & 28 (13.9) & $3(1.5)$ \\
\hline $\begin{array}{l}\text { Do you think critically ill patients or their families have } \\
\text { the right to choose to discontinue life-supporting } \\
\text { interventions? }\end{array}$ & $57(28.3)$ & $125(61.9)^{*}$ & $10(4.9)$ & $10(4.9)$ & $0(0.0)$ \\
\hline $\begin{array}{l}\text { Do you think explaining the prognosis of a terminal } \\
\text { illness imparts a sense of hopelessness in the family? }\end{array}$ & $16(7.9)$ & $75(37.1)^{*}$ & $29(14.4)$ & $67(33.2)$ & $15(7.4)$ \\
\hline $\begin{array}{l}\text { Do you feel that providing EOLC requires a certain } \\
\text { degree of emotional detachment? }\end{array}$ & 24 (11.9) & $86(42.6)^{*}$ & $43(21.3)$ & $38(18.8)$ & $11(5.5)$ \\
\hline $\begin{array}{l}\text { Do you think specific training regarding EOLC should } \\
\text { be included in the medical curriculum? }\end{array}$ & $91(45.1)$ & $92(45.5)^{*}$ & $19(9.4)$ & $0(0.0)$ & $0(0.0)$ \\
\hline
\end{tabular}

EOLC, end-of-life-care; ICU, intensive care unit

Data represented as $n(\%) ;{ }^{*}$ Most common response 
Table 4: Knowledge, comfort, and training with regard to EOLC $(n=202)$

\begin{tabular}{|c|c|c|c|}
\hline & Yes & Somewhat & Not at all \\
\hline Are you acquainted with hospice as a type of care? & $76(37.6)$ & $77(38.1)^{*}$ & $49(24.3)$ \\
\hline Are you comfortable in discussing EOLC issues with families of critically ill patients? & $86(42.6)^{*}$ & $79(39.1)$ & $37(18.3)$ \\
\hline Are you comfortable in communicating regarding organ donation in brain dead & $41(20.3)$ & $58(28.7)$ & $103(51.0)^{*}$ \\
\hline $\begin{array}{l}\text { Do you feel that the training and education you received in your medical curriculum } \\
\text { has prepared you adequately to deal with terminally ill patients and their EOLC issues? }\end{array}$ & $25(12.4)$ & $79(39.1)$ & $98(48.5)^{*}$ \\
\hline
\end{tabular}

EOLC, end-of-life-care

Data represented as $n(\%) ;{ }^{*}$ Most common response

Table 5: Comfort in discussing EOLC issues $(n=202)$

\begin{tabular}{lllll}
\hline End-of-life patient care issue & $\begin{array}{l}\text { Extremely } \\
\text { comfortable (\%) }\end{array}$ & $\begin{array}{l}\text { Somewhat } \\
\text { comfortable (\%) }\end{array}$ & $\begin{array}{l}\text { Somewhat } \\
\text { uncomfortable (\%) }\end{array}$ & $\begin{array}{l}\text { Extremely } \\
\text { uncomfortable (\%) }\end{array}$ \\
\hline $\begin{array}{l}\text { Withholding mechanical } \\
\text { ventilation }\end{array}$ & $11(5.5)$ & $68(33.7)$ & $74(36.6)^{*}$ & $49(24.3)$ \\
$\begin{array}{l}\text { Withholding blood product } \\
\text { support }\end{array}$ & $24(11.9)$ & $81(40.1)^{*}$ & $73(36.1)$ & $24(11.9)$ \\
$\begin{array}{l}\text { Withholding intravenous } \\
\text { hydration }\end{array}$ & $11(5.4)$ & $61(30.2)$ & $90(44.6)^{*}$ & $40(19.8)$ \\
$\begin{array}{l}\text { Withholding nasogastric } \\
\text { feeding }\end{array}$ & $19(9.4)$ & $66(32.7)$ & $81(40.1)^{*}$ & $36(17.8)$ \\
$\begin{array}{l}\text { Withholding parenteral } \\
\text { antibiotics }\end{array}$ & $28(13.8)$ & $63(31.2)$ & $88(43.6)^{*}$ & $23(11.4)$ \\
\hline
\end{tabular}

EOLC, end-of-life-care

Data represented as $n(\%) ;{ }^{*}$ Most common response

Table 6: Competence with patient-family interactions related to EOLC $(n=202)$

\begin{tabular}{|c|c|c|c|c|c|}
\hline $\begin{array}{l}\text { Degree of competence with } \\
\text { patient/family interactions }\end{array}$ & $\begin{array}{l}\text { Competent to perform } \\
\text { independently }\end{array}$ & $\begin{array}{l}\text { Competent to perform } \\
\text { with minimal supervision }\end{array}$ & \multicolumn{2}{|c|}{$\begin{array}{l}\text { Competent to perform with } \\
\text { close supervision/coaching }\end{array}$} & $\begin{array}{l}\text { Need further basic } \\
\text { instruction }\end{array}$ \\
\hline $\begin{array}{l}\text { Delivering bad news to a } \\
\text { patient/family member }\end{array}$ & $65(32.2)$ & $87(43.1)^{*}$ & \multicolumn{2}{|c|}{$47(23.3)$} & $3(1.5)$ \\
\hline $\begin{array}{l}\text { Discussing do not resuscitate } \\
\text { orders }\end{array}$ & $44(21.8)$ & $94(46.5)^{*}$ & \multicolumn{2}{|c|}{$55(27.2)$} & $9(4.5)$ \\
\hline $\begin{array}{l}\text { Discussing home/hospice } \\
\text { referral }\end{array}$ & $44(21.8)$ & $69(34.2)^{*}$ & \multicolumn{2}{|c|}{$79(39.1)$} & $10(4.9)$ \\
\hline $\begin{array}{l}\text { Discussing a shift in treatment } \\
\text { approach from cure to comfort }\end{array}$ & $47(23.3)$ & $81(40.1)^{*}$ & \multicolumn{2}{|c|}{$67(33.2)$} & $7(3.5)$ \\
\hline $\begin{array}{l}\text { Discussing treatment } \\
\text { withholding (e.g., antibiotics, } \\
\text { hydration, nonoral feeding) }\end{array}$ & $29(14.4)$ & $89(44.1)^{*}$ & \multicolumn{2}{|c|}{$63(31.2)$} & $21(10.4)$ \\
\hline \multicolumn{6}{|c|}{$\begin{array}{l}\text { EOLC, end-of-life-care } \\
\text { Data represented as } n(\%) ;{ }^{*} \text { Most common response }\end{array}$} \\
\hline \multicolumn{2}{|l|}{ EOLC issue } & $\begin{array}{l}\text { Extremely } \\
\text { competent }\end{array}$ & $\begin{array}{l}\text { Somewhat } \\
\text { competent }\end{array}$ & $\begin{array}{l}\text { Somewhat } \\
\text { incompetent }\end{array}$ & $\begin{array}{l}\text { Extremely } \\
\text { incompetent }\end{array}$ \\
\hline \multicolumn{2}{|l|}{ Pain assessment } & $49(24.3)$ & $111(54.9)^{*}$ & $40(19.8)$ & $2(1.0)$ \\
\hline \multicolumn{2}{|l|}{ Use of opioid analgesics } & $47(23.3)$ & $107(53.0)^{*}$ & $48(23.8)$ & $0(0.0)$ \\
\hline \multicolumn{2}{|l|}{ Use of adjuvant analgesics } & $40(19.8)$ & $112(55.4)^{*}$ & $46(22.8)$ & $4(2.0)$ \\
\hline \multicolumn{2}{|l|}{ Terminal delirium } & $24(11.9)$ & $100(49.5)^{*}$ & $68(33.7)$ & $10(4.9)$ \\
\hline \multicolumn{2}{|l|}{ Terminal dyspnea } & $37(18.3)$ & $108(53.5)^{*}$ & $53(26.2)$ & $4(2.0)$ \\
\hline \multicolumn{2}{|l|}{ Nausea/vomiting } & $56(27.7)$ & $105(52.0)^{*}$ & $37(18.3)$ & $4(2.0)$ \\
\hline \multicolumn{2}{|l|}{ Constipation } & $47(23.3)$ & $107(53.0)^{*}$ & $42(0.8)$ & $6(3.0)$ \\
\hline \multicolumn{2}{|c|}{ Sedation and anxiety } & $39(19.3)$ & $111(54.9)^{*}$ & $51(25.2)$ & $1(0.5)$ \\
\hline \multicolumn{2}{|c|}{ Knowing when to discuss withholding of treatment } & $18(9.0)$ & $104(51.5)^{*}$ & $74(36.6)$ & $6(3.0)$ \\
\hline
\end{tabular}

EOLC, end-of-life-care

Data represented as $n(\%) ;{ }^{*}$ Most common response 
most of the respondents were in strong favor of including specific training about EOLC in the medical teaching programs. Overall, the respondents expressed only moderate comfort and competency in discussing and managing EOLC situations and problems, with trend toward improvement in SRs who had more experience in their specialty or in ICU. Among all specialties, residents of anesthesia and internal medicine demonstrated more comfort and competency regarding EOLC issues. Although the ability to identify the terminally ill did not vary with designation or experience, the clinical application of EOLC increased with increase in experience.

Provision of optimal EOLC is a growing concern in India and its effectiveness is considerably influenced by the attending physicians' knowledge and awareness with regard to EOLC principles. Since the greater part of hospital deaths occur in the ICUs, it stands to reason to assess the familiarity and understanding of the ICU residents with regard to EOLC.

Our results are comparable to those of Chen et al. ${ }^{12}$ and Mohamed et al. ${ }^{13}$ in that the respondents expressed a moderate level of comfort in discussing EOLC issues with the families of critically ill patients. In contrast to the findings of Chen et al. ${ }^{12}$ and Mohamed et al., ${ }^{13}$ we found that anesthesia residents expressed more competency and comfort in dealing with EOLC. This may reflect a higher involvement of the anesthesia residents in critical care units in our hospital, resulting in more interaction with the critical and terminally ill patients in the ICUs. Changes in institutional protocols such as increase in ICU rotations may contribute to improving the comfort and competency of residents of other fields.

Lack of awareness among majority of the respondents regarding existence of Indian guidelines pertaining to EOLC reflects the need for better education and dissemination of information. This is supported by the fact that majority of our respondents stated lack of adequate information and training as the main barriers to EOLC application and were in favor of including specific training about EOLC in the medical curriculum. This need for further education and training for doctors as well as nurses was consistent with the findings of other studies. ${ }^{10,12-16}$

Vejlgaard et al. studied the attitudes of Danish doctors and nurses to palliative and terminal care and found that nurses were more likely than doctors to perceive palliative/terminal care as rewarding. ${ }^{15}$ Similar to the findings in our study, they also reported that there was a lack of education regarding palliative care among healthcare professionals. ${ }^{15}$ An Indian study conducted in 2017 to assess the attitudes, beliefs, and knowledge of nurses working in critical care setup observed that knowledge and attitude toward EOLC was influenced by the religious inclination and the work experience of the nurses. ${ }^{14}$ Improvement in knowledge of doctors with experience was also found in our study. Subsequent study can be planned to evaluate the effect of religious inclinations of the doctors on their attitude toward EOLC.

Limitations of our study include disproportionate group sizes with majority of the respondents belonging to the field of anesthesia, thereby causing difficulty in making appropriate comparisons between residents of different specialties. Also, the results from a single-center study cannot be extrapolated to other institutions. A large multicenter study would better give the overview of EOLC among doctors. Since this was a self-report questionnaire, inaccuracies in self-assessment and recall bias may also have had an impact on the study results.

We conclude, based on outcome of our study, it appears that EOLC needs to be an integral part of critical care management.
We suggest that the critical care curriculum of the different subspecialties of critical care should include EOLC session as well. An integral referral system may also be an option for various advance disease patients getting treatment from critical care specialist to make a combined decision for EOLC.

\section{References}

1. Macaden SC, Salins N, Muckaden M, Kulkarni P, Joad A, Nirabhawane $V$, et al. End of life care policy for the dying: consensus position statement of Indian Association of Palliative Care. Indian J Palliat Care 2014;20(3):171-181. DOI: 10.4103/0973-1075.138384.

2. Truog RD, Campbell ML, Curtis JR, Haas CE, Luce JM, Rubenfeld $\mathrm{GD}$, et al. Recommendations for end-of-life care in the critical care unit: a consensus statement by the American College of Critical Care Medicine. Crit Care Med 2008;36(3):953-963. DOI: 10.1097/ CCM.0B013E3181659096.

3. Papadimos TJ, Maldonado Y, Tripathi RS, Kothari DS, Rosenberg AL. An overview of end-of-life issues in the critical care unit. Int J Crit IIIn Inj Sci 2011;1(2):138-146. DOI: 10.4103/2229-5151.84801.

4. Prendergast TJ, Luce JM. Increasing incidence of withholding and withdrawal of life support from the critically ill. Am J Respir Crit Care Med 1997;155(1):15-20. DOI: 10.1164/ajrccm.155.1.9001282.

5. Sullivan A, Lakoma M, Block S. The status of medical education in endof-life care. J Gen Intern Med 2003;18(9):685-695. DOI: 10.1046/j.15251497.2003.21215.x.

6. Sprung CL, Cohen SL, Sjokvist P, Lippert A, Phelan D. End-of-life practices in European intensive care units: the Ethicus Study. JAMA 2003;290(6):790-797. DOI: 10.1001/jama.290.6.790.

7. Carlet J, Thijs LG, Antonelli M, Cassell J, Cox P, Hill N, et al. Challenges in end-of-life care in the ICU. Statement of the 5th International Consensus Conference in Critical Care: Brussels, Belgium, April 2003. Intensive Care Med 2004;30(5):770-784. DOI: 10.1007/s00134-004-2241-5.

8. Mani R, Amin P, Chawla R, Divatia J, Kapadia F, Khilnani P, et al. Guidelines for end-of-life and palliative care in Indian critical care units' ISCCM consensus Ethical Position Statement. Indian J Crit Care Med 2012;16(3):166-181. DOI: 10.4103/0972-5229.102112.

9. Myatra S, Salins N, lyer S, Macaden S, Divatia J, Muckaden M, et al. End-of-life care policy: an integrated care plan for the dying. Indian J Crit Care Med 2014;18(9):615-635. DOI: 10.4103/0972-5229.140155.

10. Sadhu S, Salins NS, Kamath A. Palliative care awareness among Indian undergraduate health care students: a needs-assessment study to determine incorporation of palliative care education in undergraduate medical, nursing and allied health education. Indian J Palliat Care 2010;16(3):154-159. DOI: 10.4103/0973-1075.73645.

11. Sharma H, Jagdish V, Anusha P, Bharti S. End-of-life care: Indian perspective. Indian J Psychiatry 2013;55(Suppl 2):S293-S298. DOI: 10.4103/0019-5545.105554.

12. Chen E, McCann JJ, Lateef OB. Attitudes toward and experiences in end-of-life care education in the critical care unit: a survey of resident physicians. Am J Hosp Palliat Med 2015;32(7):738-744. DOI: 10.1177/1049909114539038.

13. Mohamed ZU, Muhammed F, Singh C, Sudhakar A. Experiences in end-of-life care in the critical care unit: a survey of resident physicians. Indian J Crit Care Med 2016;20(8):459-464. DOI: 10.4103/09725229.188196.

14. Tripathy S, Routray PK, Mishra JC. Intensive care nurses' attitude on palliative and end of life care. Indian J Crit Care Med 2017;21(10): 655-659. DOI: 10.4103/ijccm.IJCCM_240_16.

15. Vejlgaard T, Addington-Hall JM. Attitudes of Danish doctors and nurses to palliative and terminal care. Palliat Med 2005;19(2):119-127. DOI: 10.1191/0269216305pm988oa.

16. Kassa H, Murugan R, Zewdu F, Hailu M, Woldeyohannes D. Assessment of knowledge, attitude and practice and associated factors towards palliative care among nurses working in selected hospitals, Addis Ababa, Ethiopia. BMC Palliat Care 2014;13(1):6. DOI: 10.1186/1472684X-13-6. 